\title{
Analysis of Mineralized Matrices in Calcium Bodies with and Without Bacteria in Two Species of Terrestrial Crustaceans
}

\author{
Miloš Vittori ${ }^{1}$, Vesna $\operatorname{Srot}^{2}$, Birgit Bussmann ${ }^{2}$, Felicitas Predel $^{2}$, Peter van Aken ${ }^{2}$ and Jasna Štrus ${ }^{1}$ \\ ${ }^{1}$ Biotechnical Faculty, University of Ljubljana, Ljubljana, Ljubljana, Slovenia, ${ }^{2}$ Max Planck Institute for \\ Solid State Research, Stuttgart, Baden-Wurttemberg, Germany
}

Calcium bodies are specialized organs of terrestrial isopod crustaceans (woodlice) in the family Trichoniscidae. These organs are epithelial sacs that contain an extracellular matrix, mineralized with calcium salts. Recent studies have demonstrated that the mineral content of these organs changes periodically in relation to molt, the process in which crustaceans shed their old exoskeleton and form a new one. During the preparation for molt, minerals are deposited in the calcium bodies and are resorbed during and shortly after molt $[1,2]$. As the crustacean exoskeleton contains large amounts of calcium carbonate and calcium phosphate [3], calcium bodies may function as reservoirs that allow woodlice to temporarily deposit minerals from their exoskeleton before molt and mobilize it after molt, when great amounts of calcium are needed for the mineralization of the new exoskeleton.

A recently discovered, unexpected feature of calcium bodies is the presence of large bacterial populations in them. Numerous bacteria were found to fill these organs in the cave woodlice Titanethes albus [1]. Similarly, calcium bodies in several species related to $T$. albus were found to consistently contain bacteria [4]. As demonstrated in T. albus, calcium bodies continuously accumulate calcium phosphate. During preparation for molt, an additional layer of a glassy matrix forms around the bacteria-containing central matrix. This layer contains less phosphorus than the mineral in the central matrix and is resorbed after molt [1].

A related species, Hyloniscus riparius, possesses one pair of posterior calcium bodies with bacteria and an additional pair of anterior calcium bodies that lack bacteria. While the composition and dynamics of the mineralized matrix in the bacteria-containing posterior calcium bodies resemble those in T. albus, the bacteria-free anterior calcium bodies, accumulate only calcium carbonate [2]. We have recently discovered that both bacteria-containing and bacteria-free calcium bodies are present in another woodlouse, Haplophthalmus danicus. Similar to $H$. riparius, the posterior calcium bodies contain bacteria and the anterior ones lack them in H. danicus. In this study, we compared the transient mineralized matrices in bacteria-containing and bacteria-free calcium bodies in $H$. riparius and $H$. danicus in order to elucidate possible differences in mineral composition that could provide a clue to the function of symbiotic bacteria.

We obtained energy-dispersive X-ray (EDX) elemental maps of polished resin-embedded calcium body samples from molting $H$. riparius and $H$. danicus individuals with scanning electron microscopy. This allowed us to demonstrate that the bacteria-filled posterior calcium bodies in both species contain a central matrix mineralized with calcium phosphate and an outer layer of matrix that contains less phosphorus. By contrast, the bacteria-free anterior calcium bodies contain calcium carbonate with very little or no phosphorous in both species. By combining high-resolution HAADF-STEM imaging with analytical techniques (EDX and electron energy-loss spectroscopy (EELS)) and selected area electron diffraction (SAED), we demonstrated that the calcium phosphate in the central matrix of posterior calcium bodies is in the form of nanocrystalline hydroxyapatite, while the surrounding glassy matrix contains a mixture of amorphous calcium carbonate and amorphous calcium phosphate. The matrix in the anterior calcium bodies is mineralized with amorphous calcium carbonate. 
We demonstrated that the composition of mineralized matrices in bacteria-containing calcium bodies in $H$. danicus and $H$. riparius is similar to that in $T$. albus calcium bodies. The mineralized matrix in the anterior calcium bodies of both $H$. riparius and $H$. danicus, which lack bacteria, consists entirely of amorphous calcium carbonate with very small amounts of phosphorus. Our results suggest that the presence of bacteria in calcium bodies is linked to the presence of calcium phosphate. Further studies will therefore be directed at establishing, whether the bacteria play a role during calcium phosphate deposition and resorption in these organs [5].
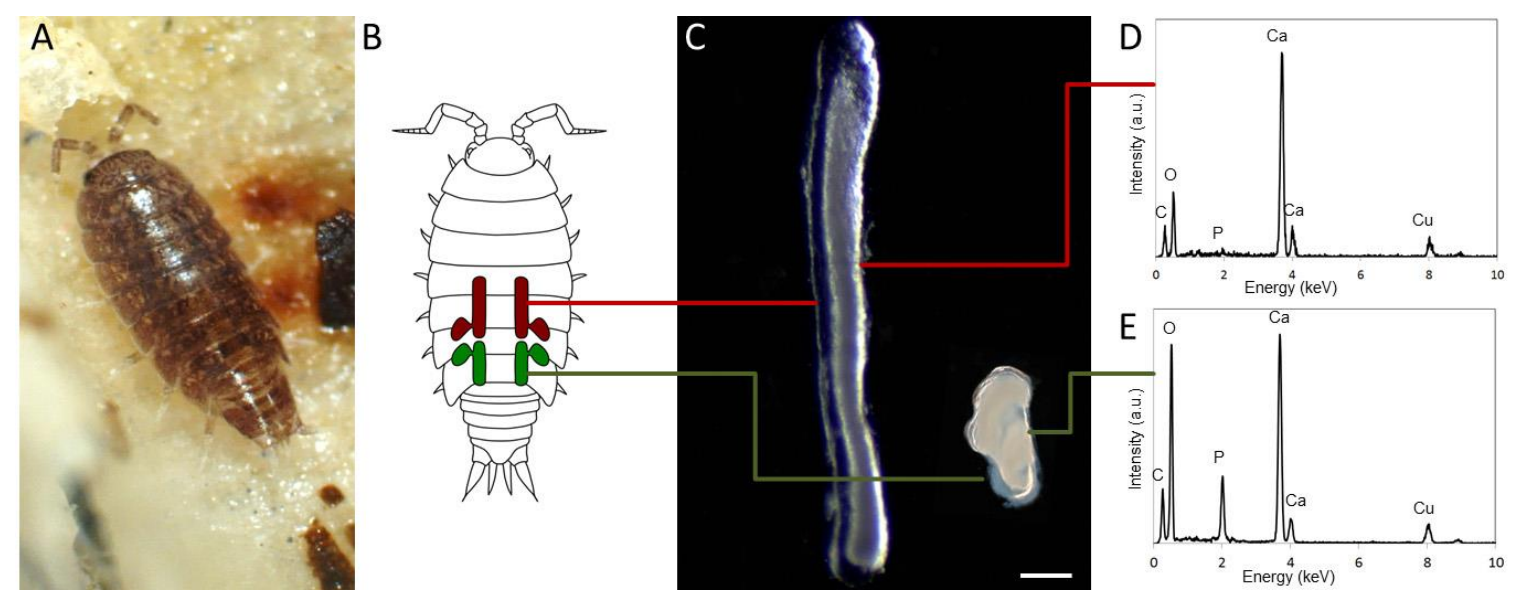

Figure 1. Calcium bodies in Hyloniscus riparius. A: The woodlouse, H. riparius. B: Position of the anterior (red) and posterior (green) calcium bodies in the animal. C: Dark-field light microscopy images of the glassy mineralized matrix in an anterior calcium body (left) and the glassy matrix layer surrounding the opaque, bacteria-containing central matrix in a posterior calcium body (right). Scale bar: $100 \mu \mathrm{m}$. D: EDX spectrum of the matrix in an anterior calcium body, containing amorphous calcium carbonate with very little phosphorus. E: EDX spectrum of the glassy matrix in a posterior calcium body with greater phosphorus content.

\section{References}

[1] M Vittori, N Žnidaršič, K Žagar, M Čeh, and J Štrus. Journal of Structural Biology 180 (2012), pp. 216-225.

[2] M Vittori, A Rozman, J Grdadolnik, U Novak, and J Štrus. PLoS One 8 (2013), e58968.

[3] M Vittori, V Srot, K Žagar, B Bussmann, P van Aken, M Čeh, J Štrus. Journal of Structural Biology 195 (2016), pp. 227-237.

[4] M Vittori, J Štrus. Acta Biologica Slovenica 59 (2016), pp. 47-55.

[5] This project has received funding from the European Union's Horizon 2020 research and innovation programme under grant agreement No. 823717 - ESTEEM3, from the Slovenian Research Agency, research program P1-0184 and the Slovenian-German bilateral project (Slovenian Research Agency BIDE/19-20-016 and DAAD PPP Slowenien 57451152). 